REVISTA DE DERECHO UNED, núm. 3, 2008

\title{
COMPRAVENTA CON EFECTOS REALES, COMPRAVENTA CON EFECTOS OBLIGATORIOS, COMPRAVENTA POR UNIDAD Y POR MEDIDA EN EL DERECHO CIVIL ITALIANO. ALGUNOS ASPECTOS A LA LUZ DE SUS ORÍGINES ROMANÍSTICOS ${ }^{1}$
}

\author{
Magda Maria Liviam Graziana Rocca
}

Dottore di ricerca in diritto civil-romanistico c/o universita' di Roma «La Sapienza»-Abogado

Resumen: La compraventa está definida en el art.1470 del Código civil italiano como aquel contrato que tiene como objeto la trasmisión de la propiedad o de otro derecho a cambio de un precio o de una compensación pecuniaria.

La transmisión del derecho de propiedad es, en general, el efecto inmediato del contrato de compraventa. El principio general que caracteriza la compraventa en el Derecho italiano consiste de hecho en la eficacia traslativa del consentimiento en tanto que efecto real del acuerdo entre las partes (art.1376c.c.), salvo algunas excepciones, entre las cuales la llamada «investidura formal del derecho", de estirpe romanística, cobra una importancia fundamental en relación con la trasmisión del mismo.

El Código civil actual también contempla, a decir verdad, supuestos en los cuales el consentimiento de las partes no produce efectos reales. En tales casos de compraventa con efectos obligatorios, que costituyen la excepción a la regla, para que tenga lugar el mencionado

La traducción al español de este artículo ha sido realizada por Elisabetta Bagli.

1 Seminario celebrado en el Instituto de Derecho romano de la UNED en Madrid, el 4 de mayo de 2007. 
efecto traslativo es necesario llevar a cabo una actividad ulterior, o bien simplemente esperar a que se verifique un determinado evento. Es lo que ocurre, por ejemplo, en los casos de compraventa de un bien ajeno, en la compraventa de cosas futuras, para la que es necesario esperar que los bienes objeto de trasmisión cobren existencia, o bien en la compraventa de cosas genericas, en relación con la cual es preciso proceder a una individualización de la cosa.

s.f. sale; transaction: (dir.) - acta, hand sale; (dir.) acto de -, deed of sale; - de patentes, de tecnologías, licensing; -...

Abstract: Sale is defined, in Art. 1470 of the Italian Civil Code, as the contract which transfers ownership or another right in exchange of a valuable consideration of the price.

Conveyance of ownership is usually the immediate effect of the sale of goods. The general rule which characterizes sale in Italian law is the effect of translation by agreement (art. 1376 c.c.), with some exceptions, in which the s.c. «investitura formale del diritto», derived from Roman law, has a basic importance for the transfer.

The Italian Civil Code includes hypothetical factual situations in which the sales agreement is without real effects. In such exceptional cases, for the transferring effect to occur, an additional activity, or simply waiting for a particular event to take place, is required.

Examples of these situations are the sale of goods not owned by the seller, or the sale of future goods, in which it is necessary to wait for the coming to existence of such goods.

The sale of goods from genus needs, instead, accomplishing an identification.

Sumario: I. Los elementos esenciales del contrato de compraventa. II. La transferencia del derecho de propiedad. III. Eficacia traslativa del consentimento IV. 1.Compraventas con efectos obligatorios IV. 2. En particular: compraventa de cosas futuras. IV. 3. En particular: compraventa de cosas genéricas. V. Compraventa por unidad y compraventa por medida. Importancia de la interpretación de la voluntad de las partes. CONCLUSIONES.

\section{LOS ELEMENTOS ESENCIALES DEL CONTRATO DE COMPRAVENTA.}

La compraventa está definida en el art. 1470 del codigo civil italiano como aquel contrato que tiene como objeto la transmisión de la 
propiedad o de otro derecho, a cambio de un precio o de una compensación pecuniaria.

Para ocuparse de ciertos aspectos peculiares de algunas formas de compraventa parece necesario remitirse al artículo $1325 \mathrm{cc}$. Dicho precepto señala, entre los elementos esenciales del contrato en general, además del objeto, también el acuerdo entre las partes, la causa y la forma, cuando esta última está prescrita por la ley so pena de nulidad. Sin embargo, la naturaleza efectiva de cada uno de estos elementos, y los rasgos que permiten distinguirlos entre sí resultan doctrinalmente controvertidos.

En relación con el contrato de compraventa, un sector de la doctrina identifica su objeto con el propio bien o derecho transferido ${ }^{2}$, mientras que, en opinión de otros estudiosos, tal objeto consiste en los intereses regulados por las partes ${ }^{3}$, o bien en el bien sobre el cual recaen los efectos negociales ${ }^{4}$. Por contra, si nos atenemos a la letra del código, el objeto del contrato de compraventa, en esencia, puede identificarse con la trasmisión del bien enajenado 5 . Según las teorías generales del contrato, a decir verdad, el objeto del mismo se concibe en ocasiones, como ya se ha señalado, como el ente real sobre el cual recaen los efectos negociales ${ }^{6}$; otras veces, sin embargo, se concibe como el contenido del contrato, es decir, como aquello que las partes han establecido y programado ${ }^{7}$; también se identifica igualmente, como ya se ha indicado, con los intereses perseguidos por las partes, volviendo inciertos los límites entre el concepto de objeto y el de causa.

También en la interpretación de la causa del contrato se contraponen en la doctrina una teoría objetiva y una teoría subjetiva. Según la teoría objetiva clásica, la más extendida, la causa de un contrato coincide con la contraprestación, es decir, con el hecho o con la cosa que constituye el fundamento de la contraprestación misma ${ }^{8}$. En la

${ }^{2}$ Si v. Messineo F. , Manuale di diritto civile e commerciale ${ }^{9}$, Milano, 1957- 1965, III,I, 1, p. 58 y ss.

${ }^{3} \mathrm{Si}$ v. BeTtI E., Teoria generale del negozio giuridico, in Trattato di Diritto Civile Italiano Vassalli $F$., Torino, 1952, ( Rist. Camerino, 1994), p. 79 y ss.

4 Cariota Ferrara L. , Il negozio giuridico nel diritto privato italiano , Napoli, 1999 , p. 607 y ss.

5 Bianca C.M., La vendita e la permuta, in Trattato di Diritto Civile Italiano Vassalli $F$., VII , t. I, Torino, 1993, pp. 3 y ss.

6 CARIOTA FerRara L. , Il negozio giuridico,cit., pp. 607 y ss.

7 BIANCA C.M., Diritto civile, III, Il contratto, Milano, 2000, p. 320.

\& Domat J., Les loix civiles dans leur ordre naturel, le droit public et legum delectus, Paris, 1777, I, V, p. 27. 
compraventa, por lo tanto, la causa parece coincidir en opinión de algunos con el precio. A la luz de la teoría objetiva, también llamada "de la función", que ve en la causa la típica función econòmico-social del contrato ${ }^{10}$, la causa del contrato de compraventa se reduce al sinalagma, al intercambio de la cosa y el precio. Interpretando la causa del contrato según la teoría subjetiva, aquélla ha de concebirse como el fin en virtud del cual las partes asumen la obligación ${ }^{11}$; en relación con el contrato de compraventa, la causa en sentido subjetivo se puede por tanto identificar con la trasmisión de la propiedad objeto del contrato de compraventa.

\section{LA TRASMISIÒN DEL DERECHO DE PROPIEDAD.}

Y la trasmisión del derecho de propiedad es, en general, el efecto inmediato del contrato de compraventa. El principio general que caracteriza la compraventa en el Derecho italiano consiste, de hecho, en la eficacia traslativa del consentimento como efecto real del acuerdo entre las partes (art.1376cc.), salvo algunas excepciones, en la cual la llamada «investidura formal del derecho» ${ }^{12}$, de estirpe romanística, cobra una importancia fundamental en relación con la trasmisión del mismo.

En el Derecho romano la compraventa nació inicialmente como intercambio contextual de cosa contra precio; se trataba por tanto de un contrato, a mi juicio más real que con efectos reales, dado que se perfeccionaba solamente con la prestación material. Del hecho que resultase indispensable el intercambio material de la cosa a cambio del precio habría quedado una huella, por otro lado, en las formalidades requeridas en la propia mancipatio, que más tarde se transformó, como señala Gayo, en una venditio imaginaria ${ }^{13}$, que exigía la

9 BIANCA C.M., Il contratto, cit., p. 449.

10 Santoro Passarelli G., Dottrine generali del diritto civile ${ }^{9}$, Napoli, 1987, p.128.

11 Capitant H., De la cause des obligations, Paris, 1927, p.19.

12 Como precisa Bianca, la investidura formal del derecho, en la experiencia romanística habría estado constituida, por ejemplo, por la entrega material del bien. Si v . BIANCA C.M., La vendita, cit., p. 82.

13 Gai. 1,113 : Coemptione vero in manum conveniunt per mancipationem id est per quandam imaginariam venditionem; nam adhibitis non minus quam $V$ testibus civibus romanis puberis, item libripende, emit enum mulier et is mulierem convenit ; Gai 1,119: Est autem mancipatio, ut supra quoque diximus, immaginaria quaedam venditio; quod et ipsum ius proprium civiumm romanorum est. Eaque res ita agitur: adhibitis non minus quam quinque testibus civibus romanis puberibus et praeterea alio eiusdem condicionis, qui libram aeneam teneat, qui appellatur libripens, is qui mancipio 
aprehensión material del bien que había de ser trasferido y que, en caso de tener como objeto una res soli, se habría desarrollado probablemente con el mismo telón de fondo ${ }^{14}$. El carácter real de la compraventa, por tanto, particularmente evidente en la trasmisión de las res nec mancipi, ya que esta última tenía lugar sólo en el momento de la traditio de la res, se hacía presente asimismo en la trasmisión de las res mancipi, dado que antes de la propia mancipatio, que formalizaba la entrega del aes rude como precio, no tenía lugar ninguna trasmisión de propiedad, ni nacían derechos de crédito sobre el propio precio $^{15}$.

Como es sabido, alrededor del tercer siglo antes de Cristo, en paralelo con la expansión del tráfico comercial y con la consiguiente necesidad de establecer y mantener relaciones comerciales con gentes procedentes de países lejanos, en el Derecho romano se planteó la exigenzcia de aligerar algunas formas contractuales y de crear obligaciones entre las partes que tuviesen como único fundamento el consenso $^{16}$. Entre los famosos contratos consensuales la emptio venditio era aquel contrato que obligaba a las partes a trasferir la definitiva disponibilidad de un bien, a cambio de su valor expresado en dinero; el traspaso material de la propiedad se producía más tarde a través de otro acto apto para ello, que podìa ser la traditio para las res nec mancipi, o bien la mancipatio par las res mancipi, o bien otro. Lo importante es que se abandonaba la necesidad de la dación del precio para que surgiese una obligación entre las partes y, obviamente, las acciones conseguientes que derivaban del incumplimiento de la palabra dada. Por un lado estaba la obligatio consensu contracta, por otro el acto materialmente traslativo de la propiedad ${ }^{17}$.

accipit, rem tenens ita dicit: "hunc ego hominem ex iure quiritium meum esse aio isque mihi emptus esto hoc aere aeneaque libra; " deinde aere percutit libram idque aes dat ei, a quo mancipio accipit, quasi pretii loco.

14 Vid. Talamanca M. , voz Vendita (dir.rom.) in ED, XLVI, 1993,p.27, n.8.

15 Vid. Talamanca M. , voz Vendita, cit., p.27.

16 G.3.136: Ideo autem istis modis consensu dicimus obligationis contrahi, quia neque verborum neque scripturae ulla proprietas desideratur, sed sufficit eos, qui negotium gerunt, consensisse. unde inter absentes quoque talia negotia contrahuntur, veluti per epistulam aut per internuntium, cum alioquin verborum obligatio inter absentes fieri non possit.

17 Precisa Bianca que el modelo romano asignaba a la compraventa un efecto meramente obligatorio, pero « la obligación del vendedor prescindía de la trasmisión de la propiedad, limitandose a la entrega ". Vid. BIANCA C.M., La vendita, cit., p. 95. Como se ha indicado, sin embargo, la entrega material del bien habría ya en sí misma determinado el efecto traslativo de la propiedad para las res nec mancipi, mientras que para las res mancipi parecería pacífico que tras la emptio venditio, fuese necesaria una mancipatio, al menos entre los que estaban legitimados para realizar tal negocio so- 


\section{EFICACIA TRASLATIVA DEL CONSENTIMIENTO}

Actualmente, como ya se ha indicado, en el sistema jurídico italiano la compraventa se configura como un contrato consensual con efectos reales, en el sentido de que el trspaso de la propiedad y también el traspaso del riesgo (dado que se aplica el principio res perit domino, recogido en el art. 1465 c.c.) tienen lugar con la mera prestación del consentimento, al margen de que haya tenido lugar o no la entrega material del bien o del precio. El art. $1373 \mathrm{cc}$. recoge así como criterio general que el acuerdo entre las partes, con tal de que haya sido manifestado legítimamente, determina por sí solo el efecto traslativo del derecho. Para que el contrato sea válido, éste debe revestir la forma prescrita en la ley so pena de nulidad de la trasmisión del derecho de propiedad relativo al bien especifico. Por ejemplo, el contrato que tiene como objeto la trasmisión de un bien inmueble requiere necesariamente, según el art. $1350 \mathrm{cc}$., la forma escrita como exigencia mínima. Los efectos reales del contrato consisten precisamente en la entrega material del bien y del precio. Tal principio, que ha encontrado su primera expresión legislativa en el Code Napoleon, ha sido, a decir verdad, atacado por parte de algunos exponentes de la doctrina italiana. Entre estos últimos, Carnelutti ha considerado que el contrato de compraventa creaba únicamente la obligación del vendedor de llevar a cabo todas aquellas actividades necesarias para realizar el traspaso efectivo de la propiedad ${ }^{18}$. La compraventa, según este autor, había de ser concebida sustancialmente como un contrato consensual con efectos obligatorios. Tal interpretación encuentra su fundamento en una formulación ambigua del art. 1448 del código civil de 1865 , según la cual sería suficiente el consentimento para hacer adquirir la propiedad "en relación con el vendedor», lo cual casi daba a entender que el consentimiento trasfería una propiedad relativa.

El código civil de 1942, en cualquier caso, no concibe el llamado "principio de separación», en base al cual se distingue la compra-

lemne. Vid. Pugliese G., Compravendita e trasferimento della proprietà in diritto romano, in ( AA.VV.) Vendita e trasferimento della proprietà nella prospettiva storico- comparatistica, I, Milano, 1991, p. 34. ; ARANGIO RUIZ V., La compravendita in diritto romano, Napoli, 1954, pp. 54 y ss.

18 Vid. CaRnelutTI F., in Riv. di Dir. Comm. 1915, I, p. 527. Aquí este estudioso precisaba che : " la propiedad no se transmite si no es en virtud de actos ulteriores, en cuyo cumplimiento está precisamente la ejecución de la obligación del vendedor ; el llamado paso de propiedad entre las partes no es sino una fórmula impropia para referirse a la obligación del vendedor relativa al cumplimiento de aquellos actos, de los que deriva dicho paso ". 
venta, en tanto que negocio obligatorio, del negocio traslativo que ha de seguir a la misma, como sucede por ejemplo en el sistema alemán ${ }^{19}$, y ya no presenta las ambigüedades del código civil precedente.

\section{IV.1. COMPRAVENTAS CON EFFECTOS OBLIGATORIOS.}

El propio código actual, sin embargo, contempla asimismo algunas hipótesis en las que el consentimiento de las partes no va seguido de efectos reales. En tales supuestos de compraventas con efectos obligatorios, que constituyen la excepción a la regla, para que se realice el ya mencionado efecto traslativo, es necesario llevar a cabo una actividad ulterior, o bien simplemente esperar a que se verifique un evento determinado. Es lo que sucede, por ejemplo, en el caso de compraventa de un bien ajeno, en la compraventa de cosas futuras, en la cual es necesario esperar a que los bienes objeto del trasmisión cobren existencia, o bien en la compraventa de cosas genéricas, en relación con las cuales es necesario proceder a una individualización.

En la compraventa de bienes ajenos, el vendedor asume sustancialmente, a través del contrato de compraventa, la obligación de permitir al comprador adquirir la propiedad del bien objeto del contrato, pariendo de que materialmente el bien que es propiedad de un tercero no podría ser objetivamente enejenado por nadie que no fuese su propietario efectivo. Quien estipula un contrato para adquirir un bien ajeno debe por tanto adquirir tal propiedad en un momento posterior al de la conclusión de dicho contrato, aunque este último haya de considerarse perfecto; tal adquisición, de hecho, tendrá lugar (por otra parte, de modo automático) sólo cuando la parte enajenante haya hecho entrar el bien en cuestión en su propria esfera jurídica. Además, si el vendedor no consiguiese adquirir el bien vendido, será responsable de incumplimiento en relación con el adquirente.

La doctrina se ha referido al «carácter incompleto" de la compraventa obligatoria ${ }^{20}$, debido precisamente a sus efectos traslativos diferidos. Tal posición no parece sin embargo inatacable si se tiene en

19 Vid. LeONHARD F., Besonderes Schuldrecht des $B G B^{15}$, Berlin, 1966, p. 13. En el ordinamiento alemán, se ha producido una separación tan neta entre el negocio obligatorio y el traslativo que la nulidad o la inexistencia de la compraventa no comprometen la validez de la trasmisión de propiedad. LARENZ K., Lehrbuch des Schuldrechts. II, 1, München - Berlin, 1968-1970, p. 12 y ss.

20 CARIOTA FERRARA L., I negozi sul patrimonio altrui : con particolare riguardo alla vendita di cosa altrui, Padova, 1936, p. 238 y ss. 
cuenta que un negocio jurídico puede en todo caso considerarse perfecto cuando estén presentes todos sus elementos esenciales ${ }^{21}$, y en una normal compraventa obligatoria es posible encontrar el acuerdo entre las partes, la causa, el objeto y, de modo abstracto, también la forma requerida para su validez, al margen de que haya o no tenido lugar materialmente la entrega de la cosa y la dación del precio.

Este último, en paricular, es considerado por parte de la doctrina como un elemento esencial, peculiar del contrato de venta que se añade a los otros previstos en el art. $1325 \mathrm{cc}$. ya mencionados y que debe ser considerado del mismo modo, dado que en ausencia del mismo la compraventa podría considerarse nula ${ }^{22}$. Al margen de que se considere el precio como requisito autónomo, o de que sea encuadrado en uno de los requisitos ya analizados en el art. $1325 \mathrm{cc}$., en función de las distintas interpretaciones que la doctrina propone para cada uno de estos requisitos, el precio, por ley, si no está ya determinado, tiene que que ser determinable; es la propia ley la que fija los criterios para su determinación, si las partes no lo han determinado. Por lo tanto, la ausencia de aprehensión material del mismo puede considerarse admitida pacíficamente y ello no parece incidir de modo autónomo en la validez de una compraventa obligatoria. Del mismo modo parecen carecer de fundamentos las dudas de parte de la doctrina acerca del carácter determinado del objeto ${ }^{23}$ en este tipo de compraventa, ya que tanto cuando se entiende que el objeto del contrato es el bien jurídico sobre el cual recaen los efectos del mismo, como cuando se entiende que el objeto es lo que las partes han establecido y programado, no parece que desaparezcan ni la identidad del objeto de la trasmisión de la propiedad, que sigue siendo el mismo al margen del momento en el que se trasfiera la propiedad, ni el hecho de que la compraventa tienda en abstacto a la trasmisión de la propiedad de un bien.

La compraventa obligatoria ha sido asimismo asimilada a una compraventa condicionada suspensivamente. En este sentido, sin embargo, se deben distinguir los casos de compraventa obligatoria de aquellos en que los efectos de la compraventa son simplemente diferidos a un momento posterior al de la celebración del contrato, pues

${ }^{21}$ Si v. Scognamiglio R., Contributo alla teoria del negozio giuridico, Napoli, 1969 , p. 264.

22 In tal senso si v . BonILINI G., I contratti relativi al trasferimento di beni, en Istituzioni di diritto privato a cura di Bessone M., Torino, 2000, p. 788.

${ }^{23}$ En este senido vid . BIANCA C.M., La vendita, cit., p.99; contra : MARTORANo F., La tutela del compratore per $i$ vizi della cosa, Napoli, 1956, p. 81, según el cual faltaría el contenido típico de la reglamentación. 
la compraventa es, en todo momento, un negocio jurídico con efectos reales y no con efectos meramente obligatorios. Cuando la eficacia de la compraventa queda subordinada, como consecuencia de un acuerdo expreso entre las partes, a que se cumpla una condición, o bien a que se cumpla un plazo, el traspaso de la propiedad del bien se realiza materialmente cuando tiene lugar el evento futuro e incierto establecido por las partes en la cláusula condicional, o bien en el momento de la fecha cierta establecida, pero se considera como si hubiese ya tenido lugar en el momento de la conclusión del contrato, dado que el artículo 1360 del código civil dispone que los efectos son, como regla general, retroactivos. Ello no ocurre exactamente igual en las compraventas obligatorias, en las cuales la eficacia del negocio jurídico no parece quedar necesariamente subordinada a que tenga lugar un evento futuro e incierto. Tal cosa, en la práctica, parece ocurrir sólo en el caso de la emptio spei, mientras que, en relación con la emptio rei speratae, o bien en la compraventa de cosa ajena, subsiste evidentemente una obligación de origen consensual que debe cumplir una de las partes, consistente en procurar y transferir a la otra parte un bien o bienes determinados. La doctrina hace referencia en este caso a una "condición legal necesaria», en contraposición a la condición a la cual las partes pueden volontariamente subordinar la eficacia de un negocio jurídico. Si en la compraventa obligatoria, no obstante, no se cumple la llamada «condición legal», ello no comporta, en general, la ineficacia del negocio jurídico, sino más bien el incumplimiento de la parte obligada a procurar y a transferir el objeto establecido en el contrato. Una emptio rei speratae, o bien una compraventa de cosa ajena, incluso en el caso en que el vendedor no produzca o no adquiera el bien destinado al adquirente, conservan su eficacia propia, hasta el punto de que el adquirente podrá actuar contra la otra parte incumplidora por esta causa. Por lo que respecta a la validez, a la eficacia y al momento de realización del acto transmisivo, es necesario en cualquier caso distinguir entre los varios tipos de compraventa obligatoria.

\section{IV.2. EN PARTICULAR: COMPRAVENTA DE COSA FUTURA.}

Entrando en la cuestión de la compraventa de cosa futura, es decir en la compraventa que concierne a un bien de hecho inexistente ${ }^{24}$

${ }^{24}$ Existen casos en los que, sin embargo, la ley impide disponer de determinados bienes que constituyen sólo una posible expectativa. Nos referimos, por ejemplo a las prohibiciones relativas a los pactos sucesorios, con los que el futuro heredero dispo- 
como objeto de derechos de disfrute, dicha compraventa abarca, según la doctrina italiana: 1) las cosas que aún no existen in natura; 2) las cosas que existen in natura pero que no son propiedad de nadie y que no pueden ser objeto de ocupación; 3) los productos de la actividad humana que todavía carecen de una individualidad económica; 4) finalmente, los productos naturales que no han sido separados de la cosa madre y que no pueden ser objeto de propiedad separada ${ }^{25}$. En la compraventa de cosa futura según el Derecho actual, la adquisición del derecho sobre el bien se produce para el comprador de manera automática, en cuanto nace el derecho mismo, siempre que ello ocurra en la esfera jurídica del vendedor, pues de otro modo éste no podría transferirlo al comprador.

En el Derecho romano la compraventa de cosa futura se concreta, como se ha indicado, en las conocidas figuras de la emptio rei speratae y de la emptio spei. En relación con ambas, surge el problema ya planteado por los juristas romanos relativo a la compraventa sin objeto. Así, como se lee en el pasaje extraído del libro noveno ad Sabinum di Pomponio: $18,1,8$, pr., no puede tener lugar una compraventa sin objeto «nec emptio nec venditio sine re quae veneat potest intellegi». En el mismo fragmento, sin embargo, el mismo jurista precisa que existirían excepciones constituidas por aquellas figuras que iban a ser denominadas por la terminología medieval, como emptio rei speratae y emptio spei.

Con la emptio rei speratae las partes subordinaban la eficacia y el alcance de la compraventa a la hipótesis de que los bienes que habían de constituir su objeto cobrasen existencia, adecuándose consecuentemente el precio a sus futuras cantidad y calidad. Este tipo de contrato era utilizado, por ejemplo, para vender los frutos naturales futuros de una plantación, o bien el partus ancillae. En tales casos sería evidente que operaba una auténtica cláusula condicional suspensiva que subordina la eficacia del contrato a que el bien o los bienes que deben ser tranferidos ${ }^{26}$ adquieran existencia.

$\mathrm{Ni}$ en el fragmento de Pomponio, ni en otros fragmentos, parece que puedan detectarse referencias explícitas a la presencia de un negocio condicionado suspensivamente. Cierta doctrina, sin embargo, deduce del pasaje citado de Pomponio la presencia de una referencia

ne de los bienes que entrarán a formar parte de su patrimonio a la muerte del de cuius y que tienen como objeo evitar la ocasión o el motivo para llevar a cabo acciones deplorables por parte del titular de semejantes expectativas.

25 BIANCA C.M., La vendita, cit., p. 373.

26 Si v. Talamanca M., voz Vendita, cit., p.344. 
al principio de la retroactividad que caracteriza la eficacia de los negocios condicionados suspensivamente ${ }^{27}$. Esta última materia resulta aún actual en el Derecho civil italiano, que prevé en primer lugar, como se ha indicado, que la eficacia del contrato derivada del cumplimiento de la condición se retrotraiga al momento de su conclusión. Este régimen prevé además que, en la hipótesis de que quien tiene interés en que la condición no se cumpla actúe de tal modo que impida su cumplimiento, se deba reconocer a la otra parte los mismos derechos, o su equivalente, que le hubiera correspondido tras el cumplimiento natural de la condición. A fin de cuentas, cuando se ha producido un ilícito, la condición se considera cumplida según el esquema de las fictiones iuris.

De naturaleza diversa es la emptio spei de la que Pomponio habla en el primer párrafo de D. $18,1,8{ }^{28}$ El jurista romano ve inicialmente en la emptio spei una compraventa completamente carente de objeto, pero supera aparentemente los problemas derivados de dicha ausencia aduciendo que en este tipo de compraventa el objeto del contrato podría, en realidad, identificarse con el azar, es decir, con el riesgo que corre el comprador. El sinalagma vendría dado esencialmente por el intercambio del riesgo por el precio. No parece, por otro lado, que ya en el Derecho romano se tratase de un contrato completamente aleatorio, dado que el vendedor estaba siempre obligado a hacer todo lo posible para procurar el bien o bienes señalados en el contrato; para que, por ejemplo, los peces fuesen capturados, tal y como se extrae del pasaje de Celso, D. 19,1,12 ${ }^{29}$. Como ha señalado la doctrina, el vendedor respondía siempre por negligencia o por dolo en caso de que no hubiese llevado a cabo la actividad necesaria para que se realizase la spes del comprador. Este régimen se ha mantenido sin cambios también en nuestro Derecho actual.

27 D. $18,1,8$, pr. ( Pomp. 9 ad Sab.) : "Nec emptio nec venditio sine re quae veneat potest intellegi. et tamen fructus et partus futuri recte ementur, ut, cum editus esset partus, iam tunc, cum contractum esset negotium, venditio facta intellegatur: ed si id egerit venditor, ne nascatur aut fiant, ex empto agi posse»; Si veda, inoltre il Kurz, «Emptio rei speratae pura oder sub condicione? ", in Labeo, 1974, pp. 194 y ss.

28 D. 18,1,8, 1 (Pomp. 9 ad Sab.): «Aliquando tamen et sine re venditio intellegitur, veluti cum quasi alea emitur.Quod fit, cum captum piscium vel avium vel missilium emitur: emptio enim contrahitur etiam si nihil inciderit, quia spei emptio est: et quod missilium nomine eo casu captum est si evictum fuerit, nulla eo nomine ex empto obligatio contrahitur, quia id actum intellegitur».

${ }_{29}$ D. 19,1,12 (Celsus 27 dig.): « Si iactum retis emero et iactare retem piscator noluit, incertum eius rei aestimandum est: si quod extraxit piscium reddere mihi noluit, id aestimari debet quod extraxit». 
Insistimos en que en la emptio rei speratae el pago del precio está subordinado a la aparición del bien y es proporcional a la cantidad del bien producido naturalmente, mientras que en la emptio spei el precio se determina globalmente, sea cual sea la cosa que cobre o no cobre existencia. Por este motivo la doctrina se ha esforzado en precisar que el negocio de compraventa de cosa futura debe calificarse como emptio spei o como emptio rei speratae en función de como las partes hayan calculado el precio ${ }^{30}$. Este último es un elemento de particular relevancia que, junto con el criterio de determinación del objeto de la prestación, parece indispensable a la hora de caracterizar y delinear las diferencias no sólo entre los diversos tipos de compraventas obligatorias sino también, como se verá, entre estas y la compraventa por unidad y por medida. Ya en época clásica romana, como sucede aún hoy, determinar si un negocio jurídico tenía como objeto la emptio spei o la emptio rei speratae dependía de la interpretación de la volutad de las partes contratantes ${ }^{31}$, pero es evidente que éste sigue siendo el criterio principal para distinguir en la práctica todos los tipos de compraventa mencionados. Piénsese por ejemplo en un conocido pasaje de Giuliano, en el que las partes parecen haber convenido una limitación al azar y, simultáneamente, una adecuación del precio a la cantidad que efectivamente llegue a cobrar existencia ${ }^{32}$.

En cuanto a las compraventas de cosas futuras, la doctrina actual presta especial atención a la distinción entre bien inexistente y bien que en ningún caso puede llegar a existir. La hipótesis de la inexistencia de hecho de la cosa es completamente distinta de la de una imposibilidad originaria del contrato. Esta última convierte el contrato en nulo, al igual que el carácter indeterminado del objeto; la primera, por el contrario, formando parte del azar del contrato, puede entrar dentro de los sucesos posibles y no es susceptible de afectar a la validez del contrato mismo ${ }^{33}$. Corresponderá al enajenante, con su acti-

30 vid. TALAmanca M., voce Vendita, cit., p.345, n. 416, quien observa que en el caso de precio determinado globalmente no es en general posible establecer cuál pueda ser el precio por unidad de medida, mientras que en el precio fijado por unidad de medida, no es posible establecer la cantidad a entregar si no es en función de la cantidad efectivamente producida.

31 En particular, ARANGio RuIz V., La compravendita, cit., p. 121.

${ }^{32}$ D. 18.1.39.1 ( Iul. 15 dig). : "Verisimile est eum, qui fructum olivae pendentis vendidisset et stipulatus est decem pondo olei quod natum esset, pretium constituisse ex eo quod natum esset usque ad decem pondo olei:idcirco solis quinque collectis non amplius emptor petere potest quam quinque pondo olei, quae collecta essent, a plerisque responsum est".

33 Bianca C.M., La vendita, cit., p. 374, y además p. 381. 
vidad, procurar que el adquirente adquiera el bien, conforme a la regla común a todos aquellos contratos en los que tal adquisición no es un efecto inmediato del contrato.

\section{IV.3. EN PARTICULAR: COMPRAVENTA DE COSAS GENÉRICAS.}

Entre las compraventas de naturaleza obligatoria se encuentra asimismo la compraventa de cosas genéricas. Se trata de un tipo de compraventa que forma parte de la compraventa de bienes muebles y que tiene como objeto cosas que se identifican exclusivamente por su pertenencia a un género y no por su identidad. La diferencia entre compraventa de cosas futuras y compraventa de cosas genéricas consiste en que la compraventa de cosas futuras es siempre la compraventa de una cosa específica, identificable con métodos ordinarios.

La compraventa de cosas genéricas puede por tanto calificarse como una compraventa obligatoria, ya que falta materialmente la referencia a los bienes concretos sobre los cuales deben recaer los efectos traslativos del consentimiento. También en este caso el consentimiento produce el efecto de obligar al vendedor a procurar al comprador esencialemente el objeto del contrato. Ello tiene lugar mediante la «individualización», que en sí misma no tiene como fin la determinación del bien porque, como se ha señalado, el bien ha sido ya determinado, aunque sólo sea en relación con su género, sino que tal individualización es concebida como el acto jurídico de asignación mediante el cual se sustancia el cumplimiento del contrato. La individualización consiste materialmente en la elección de cosas específicas y en su atribución al acreedor de la prestación que deriva del contrato. Por pertenecer a un genus, habitualmente tales bienes han de ser objeto de una "separación" de hecho de otros bienes que pertenecen al mismo género, separación que puede tener lugar mediante el uso se signos distintivos especiales. Tal individualización, cuyo objetivo es la determinación efectiva del precio, y que a la vez es en un cierto sentido una medición del bien mismo, puede realizarse mucho antes de la entrega, sin perder por ello su carácter de acto ejecutivo dirigido al cumplimiento. La aceptación por parte del comprador de los bienes individualizados ha sido equiparada por la doctrina a la simple aceptación del pago, que puede ser realizada por cualquier persona legitimada para recibir la prestación ${ }^{34}$.

${ }^{34}$ Bianca C.M., La vendita, cit., pp. 374 y ss. 
Esta misma doctrina sostiene que este tipo de compraventa solo puede tener como objeto cosas fungibles: se admite sin embargo que su objeto sean también bienes no fungibles cuando dichos bienes hayan sido determinados en el contrato en virtud de su pertenencia a un género. Recientemente la Corte di Cassazione italiana, en su sentencia n.7279 / 06, ${ }^{35}$ ha considerado que la compraventa de cosas genericas pertenecientes a un "genus limitatum" resulta admisible también en relacion a los bienes inmuebles, en virtud del principio de conservación del negocio jurídico, recogido en el art.1367 del Código civil, también respecto a los bienes inmuebles. En este ejemplo jurisprudencial, el "genus limitatum» está constituido por el complejo de un fundo determinado. La decisión citada establece que en la compraventa de un terreno que deba ser separado de un terreno mayor, y que ha sido identificado solo cuantitativamente mediante, la medida de su superficie, subsiste el requisito de la determinabilidad del objeto cuando se haya comprobado que las partes han considerado la extensión mayor de propiedad del vendedor como "genus" y la superficie vendida haya sido perfectamente individualizada en el contrato, con tal de que se haya establecido la medida de la extensión que haya de ser separada. Tal requisito de determinabilidad del objeto subsiste según la Corte cuando en el contrato están presentes aquellos elementos establecidos por las partes que pueden consistir en la referencia a datos fácticos existentes y verificables, que sirvan para identificar el terreno que se ha de transferir mediante un procedimiento técnico que concrete la separacion del fundo mayor, siendo así que la entrega de una $u$ otra parte del fundo resulte en sí misma irrelevante. Por el contrario se debe considerar que es imposible determinar el objeto exacto que se ha de tranferir cuando subsista un margen de duda relativo a la identidad del terreno vendido, y sea por tanto necesario proceder a la determinación de tal objeto mediante un pacto sucesivo.

Si para la compraventa de cosas genéricas, como se ha indicado, es necesario que las mismas hayan sido individualizadas para que se transfiera la propiedad, como establece el art. 1378 del código civil italiano, para la compraventa de cosas específicas, es decir de cosas identificadas en el momento del contrato, aunque no sea necesario una auténtica individualización, parece en ocasiones igualmente indispensable establecer la extensión material del bien objeto de compraventa, aunque sólo sea para atribuirle una calificación más precisa y un precio. A tal fin sirven los criterios de la compraventa por

35 Cass. civ., 29.03.2006, n.7279, en Obbl. e Contr., 2006, 8-9, p. 747. 
unidad, o bien de la compraventa por medida, que en el Derecho italiano se aplican solamente en los negocios traslativos cuyo objeto son bienes inmuebles. En relación con tales criterios no parecen encontrarse en las fuentes romanistas formas de compraventa que se correspondan exactamente con las del Derecho actual.

En el Derecho romano, sin embargo, entre los criterios de compraventa de cosas genéricas y los de cosas específicas, aunque sólo sea en relación con bienes muebles, es posible encontrar una multiplicidad de figuras intermedias de gran interés, que permiten comprender algunos de los pasos que conducen al régimen actual tanto de la compraventa por unidad como de la compraventa por medida.

\section{COMPRAVENTA POR UNIDAD Y COMPRAVENTA POR MEDIDA. IMPORTANCIA DE LA INTERPRETACIÒN DE LA VOLUNTAD DE LAS PARTES.}

También en relación con la compraventa de cosas individualizadas sólo en el género se planteaba en el Derecho romano el problema relativo a la determinación del objeto del contrato. Se había discutido doctrinalmente ${ }^{36}$ si en la experiencia jurídica romana estuviese realmente admitida la compraventa del llamado genus «ilimitado», mientras parece más pacífico que se admitiese la del llamado genus «limitado" ${ }^{37}$. La primera sería aquella a que se ha hecho referencia como compraventa de cosas genéricas propiamente dicha; la segunda, por el contrario, se produciría cuando el objeto de la compraventa consiste en una cierta cantidad de cosas que ha de ser extraída de una reserva determinada. Existen fuentes como el conocido texto de Papiniano extraído del tercer libro responsorum ${ }^{38}$ (Vat. Frag. 16) en donde se encuentran precisas referencias a una compraventa de vino cuya partida había sido anteriormente individualizada y que por tal motivo, se realiza probablemente per aversionem, es decir, en bloque $^{39}$. En el mismo texto, se da asimismo noticia del caso de una compraventa en la que falta la individualización y en la que el peligro

36 Vid. por todos Talamanca M., voz Vendita, cit., p.360, n. 574, a la que se remite para el debate doctrinal.

37 En este sentido, en particular, KRÜCKMANN P., Einige Randfragen zum periculum emptoris, in ZSS, 1939, p. 7 y ss.

${ }_{38}$ Vat. Fr.16: "Vino mutato periculum emptorem spectat, quamvis ante diem pretii solvendi vel condicionem emptionis inpletam id evenerit. quod si mille amphoras certo pretio corpore non demonstrato vini vendidit, nullum emptoris interea periculum erit "

39 Vid. Talamanca M., voz Vendita, cit., p.361. 
no grava al comprador, precisamente porque tal ausencia no ha determinado el traspaso de la propiedad de los bienes objeto de la compraventa a su esfera jurídica. La doctrina ha considerado que tal pasaje guarda relación con la compraventa de un cierto número de ánforas que habían de ser extraídas de un lugar determinado, de tal manera que se trataría de un genus limitado ${ }^{40}$. Según la interpretación la referencia en este pasaje a un "corpore non demonstrato" haría pensar en la presencia de un genus ilimitado ${ }^{41}$.

Existen certamente diversos fragmentos en los que la compraventa tiene como objeto por ejemplo una cierta cantidad de un cierto genus, sobre todo de vino que debe obtenerse de una cantidad mayor que se encentra en un cierto lugar ${ }^{42}$. También en este caso parece fundamental en los mismos fragmentos la interpretación de la voluntad de las partes para la regulación del asunto; en cualquier caso también en la compraventa de cosas pertenecientes a un genus limitado se plantea el problema de una ulterior individualización que en general tiene lugar con la admensio, es decir, con la medición de la cosa vendida. Es importante el pasaje del Codex 4,48,2,43 en el que se establece que antes de la traditio o de la admensio la compraventa haya de considerarse imperfecta, lo cual remite a la regla de la compraventa de cosas genéricas. El concepto de medición, sin embargo, aparece en las fuentes no solamente en la compraventa de genus limitado, sino en un tipo de compraventa que en esencia puede casi considerarse como de cosas específicas (de species). Se trata, de hecho, de la venta de bienes fungibles ya individualizados, pero que deben sólo ser medidos para determinar su precio. Esta debe considerarse esencialmente como una forma de compraventa por medida referida sin embargo a bienes muebles. Este último caso puede encontrarse en los

40 Arangio Ruiz V., La compravendita, cit., p. 123 ; Casavola F., Emptio pondere numero mensura, in Scritti giuridici raccolti per il centenario della casa editrice Jovene, Napoli, 1954, pp. 577 y ss.

41 Talamanca M., voce Vendita, cit., p.361

42 Vid. Por ejemplo: D.18.6.1.2 (Ulp. 28 ad Sab.) : "Si dolium signatum sit ab emptore, Trebatius ait traditum id videri: Labeo contra, quod et verum est: magis enim ne summutetur, signari solere, quam ut traditum videatur» o bien D. 18,6,6 ( Pomp. 9 ad Sab.): "Si vina emerim exceptis acidis et mucidis et mihi expediat acida quoque accipere, Proculus ait, quamvis id emptoris causa exceptum sit, tamen acida et mucida non venisse: nam quae invitus emptor accipere non cogeretur, iniquum esse non permitti venditori vel alii ea vendere».

${ }_{43}$ C. 4,48,2pr. : Imp. Alex A. Gargilio Iuliano.

Cum convenit, ut singulae amphorae vini certo pretio veneant, antequam tradantur, imperfecta etiam tunc venditione periculum vini mutati emptoris, qui moram mensurae faciendae non interposuit, non fuit. PP. V K. april. Maximo II et Aeliano conss. ( a 223) 
pasajes de Gayo y de Ulpiano (D. $18,1,35-36^{44}$ y D. $18,6,1,3-4^{45}$ respectivamente) y haría referencia a las cosas quae pondere, numero mensura constant, como por ejemplo las ovejas de un rebaño. Sin em-

44 D.1,1,35 (Gaius 10 ad ed. prov.): "Illud constat imperfectum esse negotium, cum emere volenti sic venditor dicit: 'quanti velis, quanti aequum putaveris, quanti aestimaveris, habebis emptum'. Veneni mali quidam putant non contrahi emptionem, quia nec societas aut mandatum flagitiosae rei ullas vires habet: quae sententia potest sane vera videri de his quae nullo modo adiectione alterius materiae usu nobis esse possunt: de his vero quae mixta aliis materiis adeo nocendi naturam deponunt, ut ex his antidoti et alia quaedam salubria medicamenta conficiantur, aliud dici potest.Si quis amico peregre eunti mandaverit, ut fugitivum suum quaerat et si invenerit vendat, nec ipse contra senatus consultum committit, quia non vendidit, neque amicus eius, quia praesentem vendit: emptor quoque, qui praesentem emit, recte negotium gerere intellegitur. Si res vendita per furtum perierit, prius animadvertendum erit, quid inter eos de custodia rei convenerat: si nihil appareat convenisse, talis custodia desideranda est a venditore, qualem bonus pater familias suis rebus adhibet: quam si praestiterit et tamen rem perdidit, securus esse debet, ut tamen scilicet vindicationem rei et condictionem exhibeat emptori. Unde videbimus in personam eius, qui alienam rem vendiderit: cum is nullam vindicationem aut condictionem habere possit, ob id ipsum damnandus est, quia, si suam rem vendidisset, potuisset eas actiones ad emptorem transferre In his quae pondere numero mensurave constant, veluti frumento vino oleo argento, modo ea servantur quae in ceteris, ut simul atque de pretio convenerit videatur perfecta venditio, modo ut, etiamsi de pretio convenerit, non tamen aliter videatur perfecta venditio, quam si admensa adpensa adnumeratave sint. Nam si omne vinum vel oleum vel frumentum vel argentum quantumcumque esset uno pretio venierit, idem iuris est quod in ceteris rebus. quod si vinum ita venierit, ut in singulas amphoras, item oleum, ut in singulos metretas, item frumentum, ut in singulos modios, item argentum, ut in singulas libras certum pretium diceretur, quaeritur, quando videatur emptio perfici. quod similiter scilicet quaeritur et de his quae numero constant, si pro numero corporum pretium fuerit statutum. Sabinus et Cassius tunc perfici emptionem existimant, cum adnumerata admensa adpensave sint, quia venditio quasi sub hac condicione videtur fieri, ut in singulos metretas aut in singulos modios quos quasve admensus eris, aut in singulas libras quas adpenderis, aut in singula corpora quae adnumeraveris. Ergo et si grex venierit, si quidem universaliter uno pretio, perfecta videtur, postquam de pretio convenerit: si vero in singula corpora certo pretio, eadem erunt, quae proxime tractavimus. Sed et si ex doleario pars vini venierit, veluti metretae centum, verissimum est (quod et constare videtur) antequam admetiatur, omne periculum ad venditorem pertinere: nec interest, unum pretium omnium centum metretarum in semel dictum sit an in singulos eos. Si quis in vendendo praedio confinem celaverit, quem emptor si audisset, empturus non esset, teneri venditorem»; D.18,1,36 ( Ulp. 43 ad ed.) : «Cum in venditione quis pretium rei ponit donationis causa non exacturus, non videtur vendere"

${ }_{45}$ D.18,6,1,3 - 4 (Ulp. 28 ad Sab.): «Licet autem venditori vel effundere vinum, si diem ad metiendum praestituit nec intra diem admensum est. effundere autem non statim poterit, priusquam testando denuntiet emptori, ut aut tollat vinum aut sciat futurum, ut vinum effunderetur. Si tamen, cum posset effundere, non effudit, laudandus est potius: eapropter mercedem quoque doliorum potest exigere, sed ita demum, si interfuit eius inania esse vasa in quibus vinum fuit (veluti si locaturus ea fuisset) vel si necesse habuit alia conducere dolia. commodius est autem conduci vasa nec reddi vinum, nisi quanti conduxerit ab emptore reddatur, aut vendere vinum bona fide: id est quantum sine ipsius incommodo fieri potest operam dare, ut quam minime detrimento sit ea res emptori». 
bargo, el tenor literal de las fuentes indica que, también en este caso, la medición parece tener como función no sólo la determinación del precio, que será calculado según una unidad de medida, sino también la conclusión del contrato mismo. Sin embargo, resulta doctrinalmente controvertido que el contrato sin la medida no sea fuente de obligaciones para las partes ${ }^{46}$, dado que los propios pasajes que acaban de citarse (Ulpiano D.18, 1,6,3-4) parecen indicar que existen deberes para las partes ya antes de la medición. Tras la misma, este tipo de contrato se perfecciona sobre todo porque, siempre a la luz de las fuentes citadas, se verifica el traspaso del riesgo del vendedor al comprador.

Entrando ya en la diferencia específica entre la compraventa por medida y la compraventa por unidad, en el actual sistema jurídico italiano, tal diferencia se comprende al confrontar los artículos 1537 y 1538 del código civil. Conforme al primer apartado del art. 1537 c.c.: "Cuando un determinado inmueble se vende con indicación de su medida y por un precio establecido a razón de una cantidad por unidad de medida, el comprador tiene derecho a una reducción del precio si la medida efectiva del inmueble es inferior a la indicada en el contrato"; el primer apartado del art. 1538 c.c. establece por su parte que: «En los casos en que el precio se determine en función del cuerpo del inmueble y no de su medida, aunque esta última haya sido precisada, no hay lugar a una disminución o a un aumento del precio, salvo que la medida real sea inferior o superior en una ventésima parte respecto a la indicada en el contrato». La indicación de la medida, como resulta evidente, puede subsistir indiferentemente en ambos tipos de compraventa dado que lo que las diferencia son las modalidades de indicación del precio.

El precio, en el caso de compraventa por unidad no guarda relación con la medida del bien, es más, en este caso se puede incluso prescindir de la medida del bien, en el sentido de que la misma se convierte en un dato más acerca de las características peculiares del bien mismo, al igual que cualquier otra de entre sus cualidades.

En la compraventa por medida, por el contrario, el precio se calcula teniendo en cuenta la extensión o las dimensiones del bien, de modo que dicho precio varía, evidentemente, si varían tales elementos. En el caso en que se venda un apartamento ya específicamente identificado, la determinación de si la compraventa haya de llevarse a cabo por unidad o por medida servirá sólo para decidir si el precio

${ }^{46}$ si v. Talamanca M., voz Vendita, cit., p.364. 
debe considerarse referido al bien tomado en su conjunto, o bien si ha sido establecido en función de la grandeza del apartamento mismo, quizás para permitir una comparación con otros inmuebles de la misma categoría, pero de diferente extensión.

Como se ha visto, a la luz de la decisión antes citada ${ }^{47}$, por lo general, en la compraventa, la medida asume una particular importancia sobre todo en aquellos casos en los que depende de ella la propia determinación o determinabilidad del objeto del contrato. Ello sucede, por ejemplo, cuando las partes deciden que los efectos de un determinado contrato recaigan no sobre un bien considerado en su conjunto, sino solamente sobre una porción del mismo, como ocurre en el caso de compraventa de una parte o una cuota de un bien, distinta en relación con el todo, sólo en virtud de su específica extensión (p. ej. las primeras treinta hectáreas del fundo X). En la mayoría de los casos, sin embargo, ha de considerarse que la compraventa a medida no sirva necesariamente para identificar el bien, dado que en la práctica la naturaleza de un bien y su efectiva extensión no están necesariamente relacionadas entre sí, exactamente como ocurre en el caso de la compraventa por unidad. La compraventa por medida, en cualquier caso, no debería considerarse como una compraventa de cosas genéricas, salvo pocas excepciones.

Según una cierta orientación doctrinal ${ }^{48}$ la compraventa por medida debería ser considerada como una excepción a la regla constituida por la compraventa por unidad, mientras que según otra doctrina la compraventa por unidad debería ser comprendida como una species perteneciente al genus de la compraventa por medida ${ }^{49}$.

En la jurisprudencia más reciente, sin embargo, no se detecta una particular relación entre los dos tipos de compraventa. La Corte di Cassazione ha precisado que el problema de la identificación del bien en general prescinde de la medida, tanto en uno como en otro tipo de compraventa, dado que el criterio fundamental de distinción entre compraventa por medida y compraventa por unidad consistiría en que la primera la medición sólo determina los límites de la cosa vendida, mientras que en la segunda la determinación del bien es independiente de la medida ${ }^{50}$.

47 Cass. civ. sez. II , 29.03.2006, n.7279 in Contratti 2006, 12, p.1117.

48 GRECo P. - COTTINo G., Della vendita in Commentario del Codice Civile, Libro IVDelle Obbligazioni, Zanichelli, Bologna. 1981, p.497

49 Bianca C.M., La vendita, cit. p. 240, n. 7; Cass. civ. 06.07 .1957 n. 2070, en Mass. Foro It. 1957.

${ }^{50}$ Cass. civ., 14.05.2004, n. 9215, en Contratti, 2004, 11, 1047. 
Esta orientación doctrinal ha subrayado la importancia de la voluntad de las partes contratantes en la interpretación del contrato a efectos de determinar el régimen aplicable al caso particular de compraventa.

\section{CONCLUSIONES}

En definitiva, como ha precisado en otras ocasiones la Corte Suprema, la compraventa por unidad se caracteriza por la referencia al inmueble que constituye su objeto considerado en su entidad global, de tal manera que el precio se establece en relación a dicha globalidad, independientemente de sus dimensiones efectivas, con la excepción del caso en que su medida real sea inferior o superior en una ventésima parte a la señalada en el contrato. Dicho en otros términos, constituye una compraventa por unidad y no por medida aquella en la cual el precio acordado no guarda ninguna relación estrecha, por ejemplo, con la extensión de un fundo, aunque la misma haya sido incluida por las partes en el contrato sólo a efectos de una mejor identificación del bien ${ }^{51}$.

Partiendo de tales premisas se debe, en consecuencia, considerar que el art. 1538 del código civil italiano tiene como objetivo regular la determinación del precio y su eventual modificación sólo cuando se dé una diferencia superior o inferior en una ventésima parte entre la medida real del inmueble y la medida indicada contractualmente.

Sólo en el caso de la compraventa por medida cobra particular importancia una inexactitud cualquiera en la indicación de la medida. Sea cual sea el alcance de dicha inexactitud, según la letra de la ley es necesaria en todos los casos una adecuación del precio. Esto, por el contrario, no sucede aparentemente en relación con la compraventa por unidad, en la que el precio no es susceptible de sufrir modificaciones a menos que la medida declarada del inmueble no diverja de la medida real en más de una ventésima parte.

La jurisprudencia de la Corte Suprema había en ocasiones interpretado el artículo 1538 del código civil aclarando que la diferencia entre la medida efectiva del terreno vendido por unidad y la medida indicada en el contrato que no superase la ventésima parte era irrelevante a efectos de la variación del precio, pero no a efectos de la in-

${ }^{51}$ Cass, civ., 18.04.1998 n. 3985, en Mass. Giur. It., 1998. 
dividualización del terreno, ya que es la propia norma la que prevé la medición del terreno ${ }^{52}$.

Pronunciándose casi en sentido contrario, esa misma jurisprudencia ha precisado posteriormente que las disposiciones en materia de compraventa por unidad (y las relativas a la compraventa por medida) regulan las relaciones entre enajenante y adquirente cuando surjan disputas acerca del precio del fundo en relación a su superficie, y no son de aplicación cuando sea preciso determinar, por ejemplo en relación con terceros que invoquen derechos reales sobre el inmueble objeto de compraventa, la superficie efectiva del inmueble ${ }^{53}$.

Según una cierta orientación doctrina ${ }^{54}$, el régimen del código civil tendría carácter residual y estaría inspirado en los principios del error de cálculo, de tal manera que habría que recurrir a él, en definitiva, en el caso de no realización de una situación diversa. Es sin duda más severa la posición del ordenamiento jurídico frente al error que se verifica con ocasión de una compraventa por medida, que frente al error en el marco de la compraventa por unidad, en razón de que en este último tipo de compraventa la voluntad de las partes está orientada a no atribuir particular importancia al elemento de la medida del bien en relación con otras de sus cualidades o, incluso, a ignorar tal elemento por completo.

En la jurisprudencia ${ }^{55}$, en materia de compraventa por unidad es pacífica la posición que sostiene que el art. 1538 c.c. ha sido formulado para eliminar contrastes y se inspira sobre todo en criterios equitativos, mantenendo que tal norma, aun teniendo carácter dispositivo, sería en todo caso derogable si las partes prueban que su voluntad ha sido que el bien objeto de la prestación, al margen de su extensión, conservase siempre un cierto precio.

A la luz de las interpretaciones de la Corte Suprema ${ }^{56}$, la norma pretende evitar la injusticia manifiesta que podría derivarse del particular tipo de determinación del precio en relación con el objeto, siempre que la injusticia derive de modo evidente del propio contrato. Cuando el precio de la compraventa se determina por la uni-

${ }^{52}$ Cass. civ., 27.03.1998, n.3240, inédita.

53 Cass. civ., 01.09.1997, n. 8327, inédita.

54 Luminoso A., La compravendita. Corso di diritto civile ${ }^{3}$, Giappichelli, Torino 2003, pp. 85-86

55 Cass. civ., 26.06.1995, n. 7238, in Corriere Giur., 1995, 8, 911

56 Cass. civ., 26.06.1995, n. 7238, cit. ; Cass. civ. 29.07.1994, n. 7144; Cass. civ., 09.07.1991, n. 7594; Cass, civ.,19.05. 2006, n.11793. 
dad, en general, la cantidad a entregar se mantiene fija, incluso cuando la medida real del bien no coincide con la fijada en el contrato. Si, por contra, la medida real resulta ser inferior o superior a la ventésima parte respecto a la indicada en el contrato, el precio debe ser adecuado para que coincida con la medida efectiva, superior o inferior.

La propia Corte ha llegado así a la conclusión de que la modificación del precio de la compraventa prescrita en el art. 1538 c.c., no es expresión de una obligación contractual, es decir derivada del contrato, sino más propiamente de una obligación que nace de la ley y que se reconduce a un caso de error de cálculo ${ }^{57}$. En particular, el art. 1538 c.c. no operaría cuando el precio estipulado en la compraventa por unidad haya estado determinado por el "dolo" del vendedor, es decir cuando el error acerca de la extensión exacta del bien sea consecuencia del engaño llevado a cabo por el vendedor, y constituye la razón que ha decidido al comprador a adquirir el inmueble por unidad y no por medida. En este último caso, por otro lado, el comprador podría muy bien solicitar la anulación del contrato en el sentido del art. 1427 c.c. ${ }^{58}$.

En cuanto a la compraventa por medida, regulada en el art. 1537 c.c. la Corte Suprema ha establecido que, fuera del caso de defccto cuantitativo de la cosa vendida, no puede incluirse en el ámbito de aplicación de este artículo el caso, netamente diverso, de la carencia cualitativa de dicha cosa, carencia en presencia de la cual el comprador puede ejercitar los recursos de la anulación o la terminación del contrato (art. 1429 n. 2 e 1497 c.c.) ${ }^{59}$.

En definitiva, cuando el bien objeto del contrato, aun estando determinado, no coincide con el que realmente es desde el punto de vista cuantitativo (o cualitativo), las determinaciones, por así decirlo, exactas no prevalecen por ley sobre las determinaciones contractuales, ya que el bien indicado por las partes en el contrato es aquel sobre el cual recaen materialmente los efectos jurídicos del contrato mismo, obviamente a menos que las propias partes no hayan establecido algo distinto de forma explícita o implícita.

Cuando el bien objeto del contrato y el bien real resultasen distintos en todo o en parte, la doctrina ${ }^{60}$ no duda en precisar que la

57 Cass civ., 09.07.1991, n.7594, in GI., 1992, I,1

58 Cass. civ., 26.06.1995, n. 7238, cit.

${ }^{59}$ Cass.civ., 27.12.1993, n.12791, inédita

60 Greco P. - CotTino G., Della vendita, cit. pp. 494- 495. 
identificación concreta del inmueble podrá influir negativamente sobre el contrato, bien como defecto de cualidad, que el legislador considera como incumplimiento, bien como vicio, bien como incumplimiento en sentido estricto, en la hipótesis de aliud pro alio.

La diferencia podrá también ser irrelevante cuando la determinación contractual no haya sido rígida y sea susceptible de ser completada, como en el caso de que la indicación de ciertas características (por ejemplo, el numero de habitaciones de un edificio) tenga mero valor descriptivo. También en este caso, sin embargo, la voluntad de las partes es el elemento principal para establecer cuál es el bien vendido y cuáles las características que el mismo debe presentar.

Como se ha indicado, el art.1537 c.c. prescribe que el comprador tiene derecho a una reducción del precio del bien si su medida efectiva es inferior a la indicada en el contrato, mientras que corresponde aumentar el precio si dicha medida resulta superior, quedando abierta la posibilidad de dejar de ser parte en el contrato cuando la medida supere en un veinte por ciento lo declarado.

Una cierta orientación doctrinal ve en la situación prevista por la norma un caso del llamado error de cálculo ${ }^{61}$. Se trata de un tipo de error que en general tiene su origen en la elaboración de los datos sensoriales, y que por tanto puede tener como objeto la medición inexacta de un inmueble, con las consecuencias que se derivan para la estimación del valor del mismo. Según el art. 1430 del código civil italiano este tipo de error no conlleva la nulidad del contrato, sino simplemente la rectificación del mismo, siempre que el error no recaiga sobre la cantidad y no haya sido determinante para el consentimiento de las partes. En efecto, el art.1537 c.c no contempla la hipótesis de la nulidad del contrato, limitándose a la posibilidad de modificación del mismo, considerando normal que en la compraventa por medida las partes, ante una modesta variación de sus atribuciones reciprocas producida por error, deseen de todos modos concluir el contrato. La posibilidad de receder, es decir, de revocar el consentimiento antes de que el contrato se haya perfeccionado, reservada a la parte que de forma inesperada resultase excesivamente gravada por la nueva prestación contractual, parece por completo residual y dirigida exclusivamente a proteger a dicha parte de la eventualidad de no poder hacer frente a una carga demasiado gravosa o, peor aún, de la posibilidad de sufrir un daño.

${ }^{61}$ Luminoso A., La compravendita, cit., p. 86 
Caso distinto sería aquel en el cual en la fase precontractual, una parte indujese a error a la otra, suministrándole información falsa acerca de las dimensiones o de la extensión del bien.

Sea cual fuere el modo en que tal inducción a error tuviese lugar, es decir dolosa o culposamente, se produciría en todo caso una lesión de la libertad negocial cuyo autor incurriría en responsabilidad precontractual, con el consiguente deber de resarcir el daño causado.

Según lo previsto en el art. 1538 c.c, a diferencia de lo que sucede en la compraventa por medida, en la compraventa por unidad no se puede proceder a aumentar o a disminuir el precio, a menos que la medida real no sea inferior o superior en una ventésima parte respecto a la indicada en el contrato. En tales circunstancias, el comprador cuya intención es contraria a aumentar el precio dispone de la alternativa de dejar de ser parte en el contrato, tal y como ocurre en la compraventa por medida.

También en esta situación se hace referencia al régimen del error de cálculo. Si el error surge durante la fase precontractual, a efectos del nacimiento de la correspondiente responsabilidad, no parece relevante que tal error sea esencial o no $^{62}$. En relación con esto último, por otra parte, ni siquiera subsistirían diferencias relevantes entre la compraventa por unidad y la compraventa por medida.

El régimen cambia si el error permanece también tras la conclusión del contrato, ya que en esta fase ulterior tal error es relevante, por ley, sólo si es esencial y reconocible. En estos casos, en efecto, al haber incidido en el proceso de formación de la voluntad dicho error se configura como vicio susceptible de provocar la nulidad del contrato mismo.

En realidad, el error que genera responsabilidad precontractual y aquel que es relevante en materia de nulidad del contrato no deben ser considerados como dos situaciones del todo distintas, ya que a menudo constituyen dos niveles de gravedad de una misma situación. De hecho, la propia lesión de la libertad negocial que genera responsabilidad precontractual puede ser también causa de nulidad del contrato si subsiste después de la conclusión del mismo. La doctrina, por tal motivo, cuenta entre los casos de responsabilidad precontractual también el relativo a la estipulación culposa o dolosa de un contrato inválido sub specie de contrato anulable. ${ }^{63}$

62 Bianca C.M., Il contratto, cit., p. 174.

63 BianCa C.M., Il contratto, cit., p. 174. 
En relación con la nulidad del contrato el error ha de considerarse reconocible como proclama el art. 1341 c.c: «cuando, en relación con el contenido, con las circunstancias del contrato, o con la cualidad de los contratantes, una persona de normal diligencia habría podido percibirlo». Esta norma ha sido interpretada por una parte de la doctrina haciendo referencia a una reconocibilidad abstracta del error. De este modo un eventual conocimiento del mismo, acaecido casualmente durante la fase de la estipulación, no bastaría para afectar al contrato en caso de que el error no fuese objetivamente reconocible $a b$ origine ${ }^{64}$.

En la doctrina italiana el error esencial es, por el contrario, aquel que recae sobre la naturaleza o el objeto del contrato, sobre la identidad del objeto de la prestación o sobre una cualidad de dicho objeto, que según la percepción comun, haya de considerarse determinante en la prestación del consentimiento.

Es posible considerar que en la venta por medida el error que recae sobre las dimensiones del bien reviste siempre el carácter de esencial, puesto que la medida del bien determina el consentimiento hasta el punto de que, ya en la fase precontractual, una mínima variación puede comportar una inmediata modificación del precio. El error que se detecta después de la conclusión del contrato de compraventa por medida, por lo tanto, en el caso en que fuese además abstractamente reconocible, podría llevar sólo a la anulación del contrato.

En relación con la compraventa por unidad, parecería que también se puede considerar que las dimensiones del bien pueden formar parte de las cualidades prometidas de la cosa objeto de intercambio, idénticas a cualquier otra caracteristica que por sí misma no fuese determinante del consentimiento, y cuya ausencia, aunque pudiese ocurrir por error, no daría lugar a un error esencial y no crearía los presupuestos para la anulación del contrato ex art 1427 c.c., sino que daría lugar a un incumplimiento parcial por parte del vendedor, del que se derivaría también el derecho del comprador a obtener el resarcimiento del daño.

En relación con los bienes inmuebles, en el sistema romanístico, como se ha indicado, no se aprecia una contraposición entre compraventa por unidad y compraventa por medida. Sin embargo, desde el punto de vista de la tutela, existen fuentes extraídas del Digesto de

${ }^{64}$ Scognamiglio R., Dei contratti in generale, in Trattato Grosso G.- Santoro PassarelliF. Giuffrè, 1967, 49. 
las que resulta que en la mancipatio de los fundos rústicos en la que una parte hubiese declarado una medida inferior a la medida real del bien, por medio de la actio de modo agri, el mancipio dans respondía por el doble de la diferencia del valor del bien ${ }^{65}$.

${ }^{65}$ D.18,1,40pr( Paul. 4 epit. Alfeni dig.) : "Qui fundum vendebat, in lege ita dixerat, ut emptor in diebus triginta proximis fundum metiretur et de modo renuntiaret, et si ante eam diem non renuntiasset, ut venditoris fides soluta esset: emptor intra diem mensurae quo minorem modum esse credidit renuntiavit et pecuniam pro eo accepit: postea eum fundum vendidit et cum ipse emptori suo admetiretur, multo minorem modum agri quam putaverat invenit: quaerebat, an id quod minor is esset consequi a suo venditore posset. Respondit interesse, quemadmodum lex diceretur: nam si ita dictum esset, ut emptor diebus triginta proximis fundum metiatur et domino renuntiet, quanto modus agri minor sit, quo post diem trigensimum renuntiasset, nihil ei profuturum: sed si ita pactum esset, ut emptor in diebus proximis fundum metiatur et de modo agri renuntiet, etsi in diebus triginta renuntiasset minore modum agri esse, quamvis multis post annis posse eum quo minor is modus agri fuisset ripetere»; D.18.1.51 ( Paul. 21 ad ed.) : "Litora, quae fundo vendito coniuncta sunt, in modum non computantur, quia nullius sunt, sed iure gentium omnibus vacant: nec viae publicae aut loca religiosa vel sacra. itaque ut proficiant venditori, caveri solet, ut viae, item litora et loca publica in modum cedant»; D. 19,1,34 di Ulpiano; D. 19,1,22, di Giuliano; D. 18,5,11 di Giuliano; D. 21,2,14 di Ulpiano , Paul. Sent 2,17,4 e 1,19,1. 